\title{
Correction to: Challenging the East Asian Development Model: Evidence from South Korea
}

\author{
Jaekwon Cha ${ }^{1} \cdot$ O. Fiona Yap ${ }^{2}$ (1)
}

Published online: 9 August 2019

(c) European Association of Development Research and Training Institutes (EADI) 2019

\section{Correction to: The European Journal of Development Research https://doi.org/10.1057/s41287-019-00227-1}

This article was published with a wrong grant number in the acknowledgments:

This work was supported by the Ministry of Education of the Republic of Korea and the National Research Foundation of Korea (NRF-2018S1A3A2075531).

Publisher's Note Springer Nature remains neutral with regard to jurisdictional claims in published maps and institutional affiliations.

The original article can be found online at https://doi.org/10.1057/s41287-019-00227-1.

\author{
O. Fiona Yap \\ fiona.yap@anu.edu.au \\ Jaekwon Cha \\ jkcha@pknu.ac.kr
}

1 Department of Political Science and Diplomacy, Pukyong National University, 45, Yongso-ro, Nam-Gu, Busan 48513, South Korea

2 Crawford School of Public Policy, The Australian National University, Canberra, ACT 2601, Australia 